\title{
Outpatient Lumbar Microdiscectomy: A Prospective Study in 122 Patients
}

\author{
Ashutosh Singhal and Mark Bernstein
}

\begin{abstract}
Background: Outpatient surgery saves the risk of nosocomial complications and health care dollars. Patients undergoing lumbar microsurgical discectomy are excellent candidates for outpatient surgery. The object of this study was to examine the feasibility of performing lumbar microdiscectomy on an outpatient protocol and to examine the potential savings associated with such a protocol. Methods: From February 1997 to September, 2001, 122 consecutive patients of the senior author were entered into a protocol of outpatient lumbar microdiscectomy. Only elective cases were considered for this study. Patients were excluded if they had significant co-morbidities, lived a significant distance out of town, or if their surgery was scheduled too late in the day. Success was defined as discharge home from the day-surgery unit approximately four hours after surgery. Results: During the study period, 150 elective lumbar microdiscectomies were performed. Twenty-four patients were excluded based on the above criteria and four patients requested not to participate in the study. Of the remaining 122, 116 successfully completed the protocol $(95.1 \%)$. Six patients were admitted from the day surgery unit; two patients with dural tears and four patients with anaesthetic side-effects. No patient was readmitted to hospital after discharge and no complications of early discharge were observed. There was a total reduction in hospitalization of 1.2 nights per elective procedure considering the 150 patients, when compared with the hospitalization times prior to outpatient lumbar microdiscectomy. Conclusions: Lumbar microdiscectomy can be performed safely as an outpatient procedure, resulting in a substantial reduction in hospitalization times.
\end{abstract}

RÉSUMÉ: La microdiscectomie lombaire ambulatoire: étude prospective de 122 patients. Introduction: La chirurgie ambulatoire diminue le risque de complications opportunistes et les coûts de santé. Les patients qui subissent une discectomie lombaire par microchirurgie sont d'excellents candidats à la chirurgie ambulatoire. Le but de cette étude était d'examiner la faisabilité d'un protocole de microdiscectomie lombaire effectuée en externe et la diminution des coûts associés. Méthodes: 122 patients consécutifs de l'auteur sénior ont été admis à ce protocole entre février 1997 et septembre 2001. Seulement les cas électifs étaient éligibles. Les critères d'exclusion étaient: une co-morbidité importante, un lieu de résidence éloigné et une chirurgie prévue en fin de journée. Le succès était défini comme un congé de l'unité chirurgicale environ quatre heures après la chirurgie. Résultats: Pendant la période de l'étude, 150 microdiscectomies lombaires ont été effectuées. Quarante-quatre patients ont été exclus sur la base des critères mentionnés précédemment et quatre patients ne désiraient pas participer à l'étude. Des 122 autres patients, 116 ont complété avec succès le protocole $(95,1 \%)$. Six patients ont été hospitalisés, soit deux patients ayant présenté une déchirure durale et quatre patients ayant présenté des effets secondaires de l'anesthésie. Aucun patient n'a été réadmis après le congé de l'unité de chirurgie ambulatoire et aucune complication n'a été observée suite au congé. Dans l'ensemble cette façon de procéder a réduit l'hospitalisation de 1,2 nuits par chirurgie élective chez ces 150 patients, par rapport au temps d'hospitalisation avant l'implantation de la microdiscectomie lombaire ambulatoire. Conclusions: La microdiscectomie lombaire peut être effectuée en externe sans compromettre la sécurité des patients, ce qui diminue substantiellement le temps d'hospitalisation.

Can. J. Neurol. Sci. 2002; 29: 249-252

In this era of escalating health care costs and increasingly limited health care resources, there has been increased interest in restraining health care costs and maximizing the benefit of each dollar spent. It has been estimated that the direct medical costs of the over 200,000 lumbar discectomies performed annually in the United States, exceeds $\$ 5$ billion US. ${ }^{1-3}$

There has been an explosive growth in the field of costeffectiveness analysis. There is now an increasing body of literature dealing specifically with the cost-effectiveness of lumbar discectomy for the treatment of herniated intervertebral discs. ${ }^{2,4,5}$ These studies suggest that the incremental (that is, above the cost of continued conservative management) cost of lumbar discectomy, is between $\$ 5,200$ and $\$ 12,500$ US including diagnostic imaging, hospitalization, surgical costs, and professional fees. The wide range in costs reflects the data from Health Maintenance Organizations, which calculate based on actual costs, rather than insurance claims and which reflect lowered surgical costs and professional fees. Malter et $\mathrm{al}^{2}$ concluded that lumbar discectomy was cost-effective, in patients

From the Division of Neurosurgery, Toronto Western Hospital, University Health Network, University of Toronto, Toronto, Ontario, Canada Received November 2, 2001. ACCEPTEd infinalform February 19, 2002. Reprint requests to: Mark Bernstein, Head, Division of Neurosurgery, Toronto Western Hospital, West Wing 4W451, 399 Bathurst Street, Toronto, Ontario M5T2S8 Canada 
with clearly defined indications for surgery, citing a cost of $\$ 12,000$ to $\$ 29,000$ US per quality-adjusted life-year gained. These numbers compare favorably to other common medical and surgical interventions, such as coronary artery bypass grafting of single vessels or medical therapy for mild hypertension. It is obvious that these cost-effectiveness numbers could be improved if one of the major costs, hospitalization, could be reduced.

There are further, difficult-to-quantify, potential benefits of outpatient procedures, with patients ambulating earlier; lower rates of thromboembolic events and decrease in incidence of nosocomial infections.

Over the past several decades there has been a trend towards shorter, less invasive surgical procedures within every surgical discipline. Examples include endoscopic bowel resection ${ }^{6}$ and laparoscopic cholecystectomy, ${ }^{7}$ arthroscopic joint surgery, ${ }^{8}$ transurethral endoscopic surgery for prostate and bladder disorders ${ }^{9}$ and cardiac angioplasty. ${ }^{10}$ In the neurosurgical arena, the transsphenoidal approach revolutionized the efficacy and complications of pituitary surgery. ${ }^{11}$ With the use of the operating microscope, lumbar microdiscectomy has joined the list of procedures that have become less invasive. Now, there is literature describing outpatient craniotomy, which is certainly a more invasive and higher-risk procedure than lumbar microdiscectomy. ${ }^{12}$

Lumbar microdiscectomy itself has been studied as a potential outpatient procedure. ${ }^{13-20}$ However, only two of these eight case series were prospective. ${ }^{14,15}$ This study is unique in that it aims to analyze the effectiveness of an outpatient protocol in a single surgeon's practice and to estimate the cost benefits realized when compared with a traditional, in-patient procedure.

This study was prospectively undertaken to examine the feasibility of performing lumbar microdiscectomy as an outpatient procedure.

\section{MATERIALS AND METHODS}

All patients in the study were from the neurosurgical practice of the senior author. From February 1997 to September 2001, 122 consecutive patients were selected for inclusion in the study. During that time period, the senior author performed a total of 150 elective lumbar microdiscectomies. Patients were excluded if they had significant medical co-morbidities, lived a significant distance out of town, or requested not to have lumbar disc surgery as an outpatient procedure. In the office, pre-operatively, consent for the procedure was obtained from each patient and, at this time, the day-surgery protocol was explained. In every case, it was ensured that a family member or close friend would be present to stay with the patient overnight, in case the patient needed any assistance.

Patients were admitted to the Day Surgery Unit (DSU) at 06:30 a.m. on the day of surgery. General endotracheal anaesthesia was administered using modern short acting drugs. Induction is generally achieved with propofol (Baxter Healthcare, Glendale, CA, USA) and the narcotic analgesic usually used is fentanyl (Wyeth-Ayerst, Philpadelphia, PA, USA). A short-acting non-depolarizing muscle relaxant such as rocuronium (Organon Inc., West Orange, NJ, USA) is used along with inhaled desflurane (Ohmeda, Tewksbury, MD, USA) and nitrous oxide. Administration of prophylactic antibiotics was routinely given - cefazolin (SmithKline Beecham, Maryland Heights, MO, USA) or vancomycin (Lilly, Indianapolis, IN, USA) if the patient had a penicillin allergy.

The patient was positioned in the knee-chest position, and microsurgical lumbar discectomy and foraminotomy were performed, including removal of any free fragments and as radical a clean-out of the disc as possible. ${ }^{21}$ In our hospital electrophysiological monitoring, either with SSEP or EMG, is standard for every lumbar discectomy.

Postoperatively, the patients were observed in the postanaesthetic care unit (monitored-bed) where they were given fentanyl for pain control as well as oxygen by face mask. Then, if stable after $60-90$ minutes, they were transferred back to the DSU. The senior author examined each patient in the DSU, ensuring that the patients were fit for discharge (ie. adequate ambulation, pain control, voiding). In each case, patients were observed in hospital for a minimum of four hours prior to discharge. A prescription for acetaminophen with codeine, or similar oral medication was provided. All patients were seen in follow-up in the surgeon's outpatient clinic, four to six weeks postoperatively. Data on the procedures were prospectively entered into a database.

\section{RESUltS}

During the study period, 150 patients underwent elective lumbar microdiscectomy by the senior author. There were 28 patients excluded from the outpatient surgery protocol, as follows: seven patients with medical co-morbidities (two with angina, two with insulin-dependent diabetes and one each with congestive heart failure, narcotic addiction, and significant movement disorder), 15 patients lived a significant distance out of town, two patients had their surgery scheduled too late in the day after the evening closure of the DSU and four patients requested not to participate in the outpatient lumbar microdiscectomy protocol. The mean length of stay in hospital for the 28 excluded patients was 2.4 nights (66 nights in 28 patients).

In the 122 patients who participated in the study, the mean age was 44 years (range 23-74). Seven patients were having a second operation at the same level, one patient was having an operation at two levels and one patient was having a bilateral decompression at the same level. The other 113 patients were having unilateral, one-level, first time operations, in all cases keyhole laminotomy, discectomy, and foraminotomy.

Out of 122 patients in the study, 116 patients successfully completed the day-surgery protocol $(95.1 \%)$, the other six being admitted to hospital. Two patients were admitted for observation for cerebrospinal fluid (CSF) leak following intra-operative dural breach. Neither patient developed a subsequent CSF leak. Three patients were admitted for minor anaesthetic/general operative side-effects - two cases of severe nausea and vomiting, and one case with urinary retention, briefly requiring in and out catheterization. The final patient who failed the day-surgery protocol had severe laryngospasm postoperatively and required re-intubation. This subsequently resolved and the patient was discharged home four days later. The mean length of stay in hospital for these six admitted patients was 2.0 nights.

None of the 116 patients who successfully completed the day- 
surgery protocol required readmission to our hospital or any other prior to electively scheduled follow-up. Only two patients required medical attention prior to follow-up. One patient with a "red wound" was seen by a family doctor and given a short course of oral antibiotics; at follow-up in our clinic, no signs of a wound infection were noted. A second patient developed an early postoperative foot drop, despite having had an L5/S1 discectomy. An urgent MRI was obtained, which revealed an adequate discectomy and no visible cause of the foot drop. Overall, in the 116 patients, no complications of early discharge were noted.

For comparison purposes, we analyzed the length of hospital stay in the 50 lumbar microdiscectomy patients (elective cases only) prior to the commencement of the study. This showed that the average length of stay, in nights, was 1.6. In the 150 elective lumbar microdiscectomy cases performed during this study period, the mean length of stay was 0.4 nights (66 nights in 150 cases), a reduction of 1.2 nights per patient (ie. $1.6-0.4)$. This number gives an estimate of the reduction that might be expected by the implementation of this protocol, in the real world setting where some patients may not be suitable for outpatient lumbar discectomy. In our hospital, the cost of one night in a surgical ward bed is estimated to be $\$ 1200 \mathrm{CDN}$ so the savings according to the above analysis would be $\$ 1440 \mathrm{CDN}$ per patient.

\section{Discussion}

The feasibility of outpatient lumbar microdiscectomy has been demonstrated by this prospective case series. A previous series of 75 patients demonstrated this for outpatient conventional discectomy. ${ }^{22}$ However, in that study no reoperative cases were considered, older patients were excluded, and only "relatively stoic" patients were included. Another study described the transition from inpatient to outpatient surgery and performed a cohort analysis suggesting that patient education and low-dose perioperative narcotics were the main factors in patients successfully completing a day-surgery protocol. ${ }^{14}$ One prospective study in the literature aims to quantify the savings to third party reimbursers. ${ }^{15}$ Our study was performed in a nationalized health care system, with a single payer. We have attempted to specifically examine the savings, in terms of hospitalization nights, realized in a single surgeon's practice, over a non-outpatient approach to this procedure. Our study demonstrates that the majority of patients can be selected for the day-surgery protocol and that the benefit, in terms of hospitalization, when examined in the entire elective case population, is substantial, with a reduction of 1.2 nights per elective patient. In his series, Newman, ${ }^{22}$ suggested that the costsavings of outpatient discectomy was between $\$ 5000$ and $\$ 7000$ US (based on insurance charges). Even with a conservative estimate of an incremental cost (over and above that of the DSU) of \$1200 CDN per hospital bed per night, the cost savings are substantial - $\$ 1200 \mathrm{CDN}$ x 1.2 x $150=\$ 216,000 \mathrm{CDN}$, in only one surgeon's practice over four years.

This study was not specifically designed to gauge patient satisfaction with the use of a validated instrument, but it is worth noting that none of the 116 patients who completed the protocol openly expressed dissatisfaction with their treatment, only four patients declined to participate, and numerous patients volunteered that they were glad to have the opportunity to have the surgery as an outpatient procedure. Another possible benefit of outpatient discectomy is decreasing the chance of cancellation of an elective surgical procedure due to lack of availability of nursed beds on any given day with possible resultant decrease in waiting times for surgery.

There are excellent reviews of the complication rate of lumbar discectomy. ${ }^{23,24}$ In Ramirez' study, ${ }^{23}$ after a review of 28,395 cases, the mortality rate was found to be 5.9 per 10,000 . These 16 deaths were caused by septicemia, pulmonary embolism and myocardial infarction. In general, patients must be educated as to the signs and symptoms of these conditions, and be told to return if they develop. It is worth noting that these complications are most commonly seen after the first 24 hours, and that a routine one night admission would not necessarily decrease the incidence, or mortality rates associated with these complications.

One rare, but important complication is major vascular injury, after breach of the anterior longitudinal ligament. Ramirez ${ }^{23}$ reported an incidence of $1.6 / 10,000$ of this complication. If this complication is not recognized intraoperatively, then the postoperative examination in the DSU must consider this possibility. Patients must again be educated regarding the symptoms of this complication and told to return if they develop. Another complication of lumbar discectomy is urinary retention. Observation in the DSU would be quite sensitive to this complication and patients are not discharged until they can void.

We conclude that lumbar microdiscectomy can be performed safely as an outpatient procedure. Out of 150 elective cases, 122 were selected for outpatient surgery and 116 were successfully discharged on the day of surgery. Compared with the same surgeon's practice prior to the commencement of this study, there was a reduction in hospitalization of 1.2 nights per elective procedure with concomitant significant cost savings to the hospital and system. Detailed satisfaction surveys are needed to make sure there are no hidden human costs of outpatient lumbar microdiscectomy.

\section{REFERENCES}

1. Hanley EN. The cost of surgical intervention for lumbar disc herniation. In: Weinstein JN, (Ed.) Clinical Efficacy and Outcome in the Diagnosis and Treatment of Low Back Pain. New York, NY: Raven Press, 1992: 125-133.

2. Malter A, Weinstein J. Cost-effectiveness of lumbar discectomy. Spine 1996; 21:69S-74S.

3. Taylor VM, Deyo RA, Cherkin DC, Kreuter W. Low back pain hospitalization. Spine 1994; 19:1207-1212.

4. Clark RE. Understanding cost-effectiveness. Spine 1996; 21:646650.

5. Shvartzman L, Weingarten E, Sherry H, Levin S, Persaud A. Costeffectiveness analysis of extended conservative therapy versus surgical intervention in the management of herniated lumbar intervertebral discs. Spine 1992; 17:176-181.

6. Canin-Endres J, Salky B, Gattorno F, Edye M. Laparoscopically assisted intestinal resection in 88 patients with Crohn's disease. Surg Endosc 1999; 13:595-599.

7. Poole GH, Yellapu S. Acute laparoscopic cholecystectomy. A case controlled study. Surg Endosc 2000; 14:106-109.

8. Kirkley A, Griffin S, Richards C, Miniaci A, Mohtadi N. Prospective randomized clinical trial comparing the effectiveness of immediate arthroscopic stabilization versus immobilization and rehabilitation in first traumatic dislocations of the shoulder. Arthroscopy 1999; 15:507-514.

9. Donovan JL, Peters TJ, Neal DE, et al. A randomized trial 
comparing transurethral resection of the prostate, laser therapy and conservative treatment of men with symptoms associated with benign prostatic enlargement: The ClasPstudy. J Urol 2000; 164:65-70.

10. Canto JG, Every NR, Magid DJ, et al. The volume of primary angioplasty procedures and survival after acute myocardial infarction. N Engl J Med 2000; 342:1573-1580.

11. Faria MA, Tindall G. Transsphenoidal microsurgery for prolactinsecreting pituitary adenomas. J Neurosurg 1982; 56:33-43.

12. Bernstein M. Outpatient craniotomy for brain tumor: a pilot feasibility study in 46 patients. Can J Neurol Sci 2001; 28:120124.

13. An HS, Simpson JM, Stein R. Outpatient laminotomy and discectomy. J Spinal Disorders 1999; 12:192-196.

14. Bednar DA. Analysis of factors affecting successful discharge in patients undergoing lumbar discectomy for sciatica performed on a day-surgical basis: a propective study of sequential cohorts. J Spinal Disorders 1999; 12:362-369.

15. Bookwalter JW, Busch MD, Nicely D. Ambulatory surgery is safe and effective in radicular disc disease. Spine 1994; 19:526-530.
16. Cares HL, Steinberg RS, Robertson ET, Caldini P. Ambulatory microsurgery for ruptured lumbar discs: Report of ten cases. Neurosurgery 1988; 22:523-526.

17. Kelly A, Griffith H, Jamjoom A. Results of day-case surgery for lumbar disc prolapse. Br J Neurosurgery 1994; 8:47-49.

18. Rogers LA. Outpatient microsurgical management of ruptured lumbar discs. N C Med J 1987; 48:117-120.

19. Rogers LA. Outpatient microdiscectomy. Neurosurgery 1988; 23:128.

20. Zahrawi F. Microlumbar discectomy - Is it safe as an outpatient procedure? Spine 1994; 19:1070-1074.

21. Silvers HR. Microsurgical versus standard lumbar discectomy. Neurosurgery $1988 ; 22: 837-841$.

22. Newman MH. Outpatient Conventional Laminotomy and Disc Excision. Spine 1995; 20:353-355.

23. Ramirez L, Thistead R. Complications and demographic characteristics of patients undergoing lumbar discectomy in community hospitals. Neurosurgery 1989; 25:226-238.

24. Stolke D, Sollmann WP, Seifert V. Intra- and postoperative complications in lumbar disc surgery. Spine 1989; 14:56-64. 